\title{
THE ROYAL SOCIETY OF
}

\section{E D IN B UR G H}

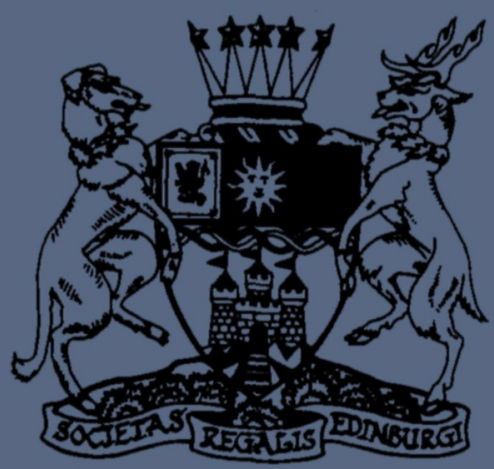

PROCEEDINGS SECTION A

M A T H E M A T I C S

PUBLISHED BY THE RSE SCOTLAND FOUNDATION 22 GEORGE STREET, EDINBURGH EH 22 PQ 


\section{EDITORIAL BOARD}

\section{Executive Editors}

E. G. REES (Chairman)

University of Edinburgh

J. M. BALL

University of Oxford
K. J. BROWN

Heriot-Watt University

A. M. SINCLAIR

University of Edinburgh
K. A. BRown

University of Glasgow

J. M. HowIE

University of St. Andrews

H. K. MoffatT

Isaac Newton Institute for

Mathematical Sciences, Cambridge
A. J. MACINTYRE

University of Oxford

O. PenRose

Heriot-Watt University

D. M. SLOAN

University of Strathclyde

M. ANDERSON

Curator

University of Edinburgh

\section{Consulting Editors}

\section{H. BREZIS}

Université de Paris VI, France

C. M. Dafermos

Brown University,

Providence, RI, USA

S. K. Donaldson

University of Oxford, UK

R. G. Douglas

State University of New York at

Stony Brook, USA

L. E. FRAENKEL

University of Bath, UK

M. GIAQUINTA

Università di Pisa

Italy

J. K. HALE

Georgia Institute of Technology,

USA

K. KIRCHGASSNER

Universität Stuttgart, Germany

ROBERT V. KOHN

New York University, USA

P. L. LIONS

Université de Paris IX, France

H. Matano

University of Tokyo,

Japan

M. MimurA

Okayama University,

Japan
O. A. OLEINIK

Moscow State University, Russia

A. Yu. OlshanskiI

Moscow State University,

Russia

D. S. Passman

University of Wisconsin-

Madison, USA

J. M. SANZ-SERNA

Universidad de Valladolid, Spain

W. G. Strang

Massachusetts Institute of

Technology, Cambridge, USA

C. A. Stuart

École Polytechnique Fédérale

de Lausanne, Switzerland

L. TARTAR

Carnegie-Mellon University,

Pittsburgh, USA

J. TOLAND

University of Bath, UK

N. S. TRUDINGER

Australian National University, Canberra, Australia

G. Q. ZHANG

Peking University, Beijing, China

W. A. ZHENG

University of California, Irvine, USA

The Royal Society of Edinburgh Proceedings Section A Mathematics is published every two months by the RSE Scotland Foundation. Subscription price is $£ 230.00$ for six issues (vol. 128). Orders, claims etc. should be addressed to CAB International, Wallingford, Oxon OX10 8DE, U.K. (Tel: (01491) 832111; Fax (01491) 826090) 